\title{
The Impact of Mood on Consumer Impulsiveness
}

\author{
Dr. Michael S. Pepe \\ Associate Professor of Marketing \\ Siena College \\ 515 Loudon Rd, Loudonville, NY 12211, USA \\ Daniel C. Buff \\ Business Development Specialist \\ Lingua Linx
}

\begin{abstract}
This research investigated consumer susceptibility to impulsive spending in a shopping environment and assessed whether mood, as well as other potential variables, affected judgment at the point of purchase. The research objectives were developed to determine if mood affects a consumer's impulse buying tendency and willingness to spend money that they originally did not plan. In addition, we also researched whether a "pleasant" consumer is more willing to spend more money than an "unpleasant" consumer is. Classifying "pleasant" and "unpleasant" consumers was made possible by using John Mayer's Brief Mood Introspection Scale (BMIS), which separates sixteen different moods into these two categories. After administering the survey and analyzing the data, the findings indicate there is a positive relationship between a "pleasant" consumer and their willingness to spend more money. In addition to this finding, it was also found that "pleasant" consumers will be more susceptible to making impulsive spending decisions. Based on these findings, businesses need to emphasize situational influences that cause "pleasant" moods amongst their customers during their time at the store and at the point of purchase. Our findings did not find any demographic variables such as education, age, gender, and income on impulsive purchasing decisions.
\end{abstract}

Keywords: impulsive behavior, mood behavior, retailing, brief mood introspection scale

\section{Introduction}

Impulse buying is the unseen side of customer behavior (Bahrainizadeh and Rajabi., et al. 2016) and is a dominant component of consumer behavior and a vital concept for businesses to understand. Impulse buying is important to businesses and their profitability as it represents a large percentage of purchases across a broad category of products. Approximately two thirds of buying decisions are impulse buys (Verplanken and Sato et al., 2011).Because of the magnitude of impulse purchases; it is relevant for marketers to grasp elements, including consumer related antecedents that drive impulse buying. The purpose of this study is to understand the impact of consumer mood on impulsive buying tendency and urge to buy in a retail environment. Impulse buying is an unplanned intent to buy products without much information checking or knowledge processing. Consumers, while making impulse purchases, are in a frame of mind that they are not thinking much about the product or not comparing the product. This type of shopping behavior can be described as an emotional mood enhancement activity with the decision to act spontaneously after seeing the product in the retail outlet (Mathai \& Shanthaamani, 2016).

\section{Literature Review}

Emotion is defined as an affective reaction, either attraction or aversion, to perceptions or situations. Richins (1997) generated a research study measuring the emotions felt during the consumption process and in the general shopping context. The study explained the role of positive emotions as goodness, happiness and excitement, in creating a pleasurable and memorable customer experience and results from this research stream have demonstrated that consumers' emotional states may influence attitude formation, intentions, behavior, and decision making (Chaudhuri). It has been observed that retail environment influence moods of the shoppers. (Bagdare \& Jain, 2013) 
The hypothesis proposed by Richins that "emotion is viewed as a valenced affective reaction to perceptions of situations" (Richins 1997) is very important when approaching the managerial implications of our study. It tells us that a consumer's mood is based off perceptions of situations around them, if a manager could find a way to influence those situations, there might be a better chance of selling the product to the consumer. Using this hypothesis, and excluding results that come from interest, surprise, sleepiness, droopiness, self-confidence and abandonment, Richins assesses the range of emotions that are most frequently experienced in consumption situations.

After several attempts and procedures, it was evident that those consumption situations in which sentimental value of the product was evident, those consumption emotion sets emphasizing sentiment, showed greater predictive validity than those associated with negative feelings, such as anger or fear (Richins, 1997). This result helped us shape our hypotheses and gave us the idea that products that give the consumer a feeling of sentimental value cause consumers to pay more money, and products that evoke negative feelings cause them to spend less.

The prior study done by Richins (1997) was very important towards our research as it gave a range of emotions involved with consumer spending. The study consists of 16 identifiable clusters that are comprised of 43 descriptors in total (items.) These descriptors identify a massive range of "emotions" from anger to happiness that assisted us when deciding which emotions to focus on with consumer spending. Richins (1997) gives us an idea of the most prevalent emotions present when a consumer purchases something.

When determining our mood scale, we chose a "Brief Mood Introspection Scale: BMIS" (Mayer, 1988). This study presented mood as being comprised of two elements, the direct experience of the mood, and mood as a result of thoughts or feelings referred to in the study as the "Meta level". This study separated 16 different moods into "pleasant" and "unpleasant" categories

Puri's “Consumer Impulsiveness Scale: CIS" (Puri 1996) was used in our study as it centers on consumer impulsivity. Puri's research objective was similar to our own in which she was trying to determine if consumers impulsive decisions were determined by "chronic values or situational characteristics" (Puri 1996). Using this logic she developed a two factor method consisting of a "prudence" subscale composed of seven items, and a "hedonic" subscale, composed of an additional five items (Puri 1996). These same 12 items from her subscales were in incorporated into the first question in our survey on a 7-point Likert fashioned scale, just as Puri had done in her research. With these sources, we sufficiently gathered secondary data pertaining to the variables established in our conceptual model and were able to use those to help shape our scales to provide us with extremely accurate and thorough results.

\section{Demographic Characteristics and Impulse Shopping Behavior}

Several studies have found that demographic characteristics of consumers impact impulse shopping behavior. Research results by Tifferet \& Herstein (2012) and Anic et al. (2010) found that females are more impulsive shoppers than males. Higher income consumers are likely, because of less budgetary concerns, to act on impulse (Vipul, 2010), but there is some confirmation that low income consumers are highly impulsive (Shukla et al., 2011). Older shoppers do more planning and are likely to be less susceptible to in-store stimuli and less likely to be impulsive shoppers (Zeithaml, 1985). Regarding education levels of consumers, previous studies have produced different results. A study by Vipul (2010) found that high educated consumers were more likely to be impulse shoppers and other studies (Shukla et al. , 2011) found that less educated education consumers are highly impulsive.

\section{Hypotheses}

Initiating from the theoretical bases, research topic, and established aims, as well as from the previous research results, the following hypotheses are formulated:

H1: "Pleasant" consumers will be more susceptible to making impulsive decisions compared to "unpleasant" consumers.

H2: Pleasant" consumers will spend more money than "unpleasant" consumers

H3: Demographic variables such as education, age, gender, and incomemake a consumer more susceptible to making an impulsive purchasing decision. 


\section{Research Design}

For our research design, a variety of exploratory, descriptive, and causal research were used to collect and analyze our data. We used exploratory research to gain a deeper understanding of our hypotheses, thoughts, feelings, and motivations of each respondent. During our literature review, we used multiple studies from the past that were like our study to develop scales, ideas, and better shape our research problem. We gathered our descriptive research using a detailed survey. By putting most of the questions on a scale, we were able to retrieve numeric data that analyzed each respondent by their purchasing behaviors. Finally, we used causal research when designing our research questions to gather primary data. Oftentimes, we would ask the respondent, "When I am (Happy, Sad), I tend to spend more money." This question is an example of a cause and effect question. This type of research was extremely important to our study because it offered us an opportunity to assess and explain the cause and effect among moods and their impact on spending behavior.

\section{Scales and Validation}

The Consumer Impulsiveness Scale: CIS" (Puri 1996) was used to measure the impulsive behavior of respondents. Impulsivity was the dependent variable in this study with "pleasant" and "unpleasant" consumers representing the independent variables. Using the Brief Mood Introspection Scale (BMIS) (Mayer, 1988) we narrowed down moods into two categories, "pleasant" and "unpleasant. The BMIS is one of the most commonly used measures of mood in psychological studies (Preeshl, George \& Hicks, 2015).This scale includes 16 items that are usually rated on a 4-point rated ("definitely do not feel" to "definitely feel"). . The items contain eight positive (active, calm, caring, content, happy, lively, loving, and peppy) and eight negative mood (drowsy, fed up, gloomy, grouchy, jittery, nervous, sad, and tired) positions. The items can be combined in various ways to arrive at four subscales, namely pleasant-unpleasant, arousal-calm, positive-tired, and negative-relaxed. A higher number demonstrates a higher positive mood.(Ho et al, 2015).We modified this scale so that each mood, was covered by an individual item, and then measured on a 7-point Likert fashioned scale. The "pleasant", and "unpleasant" moods were separated by a page break so that "pleasant" moods were addressed followed by "unpleasant" on the next page. The study done by Mayer is done in a similar fashion, splitting the "pleasant" and "unpleasant" categories when addressing respondents. The CIS and BMIS scale used in this study can be found in the appendix.

\section{Survey Design and Implementation}

Our survey consists of 9 items collecting a wide range of data including the CIS scale, the BMIS scale, causal research questions, descriptive research questions, demographics and screening questions. The survey was administered online via Qualtrics software and a total of 207 respondents provided complete answers.

\begin{tabular}{|c|c|c|c|c|c|}
\hline \multicolumn{3}{|c|}{ Age } & \multicolumn{3}{|c|}{ Gender Identity } \\
\hline $18-24$ & 116 & $56.0 \%$ & Woman & 114 & $51.1 \%$ \\
\hline $25-34$ & 36 & $17.4 \%$ & Man & 89 & $39.9 \%$ \\
\hline $35-45$ & 10 & $4.8 \%$ & Transgender & 1 & $0.4 \%$ \\
\hline $46-55$ & 27 & $13.0 \%$ & Other & 2 & $0.9 \%$ \\
\hline $56-65$ & 9 & $4.3 \%$ & Would rather not disclose & 1 & $0.4 \%$ \\
\hline \multirow[t]{3}{*}{65 or older } & 9 & $4.3 \%$ & & & \\
\hline & & & \multicolumn{3}{|c|}{ What Country Do You Reside In? } \\
\hline & & & United States & 200 & $96.6 \%$ \\
\hline \multicolumn{3}{|c|}{ Annual Household Income } & Antigua and Barbuda & 1 & $0.5 \%$ \\
\hline Under $\$ 20,000$ & 26 & $12.6 \%$ & Brazil & 1 & $0.5 \%$ \\
\hline $20,000-39,999$ & 14 & $6.8 \%$ & India & 1 & $0.5 \%$ \\
\hline $40,000-59,999$ & 21 & $10.1 \%$ & Liberia & 1 & $0.5 \%$ \\
\hline $60,000-79,999$ & 12 & $5.8 \%$ & Netherlands & 1 & $0.5 \%$ \\
\hline $80,000-99,999$ & 22 & $10.6 \%$ & Sweden & 1 & $0.5 \%$ \\
\hline $100,000+$ & 72 & $34.8 \%$ & Other & 1 & $0.5 \%$ \\
\hline Would rather not disclose & 40 & $19.3 \%$ & & & \\
\hline \multicolumn{3}{|c|}{ Highest Level of Education } & & & \\
\hline High School/GED & 8 & $3.9 \%$ & & & \\
\hline Some College & 63 & $30.4 \%$ & & & \\
\hline 2- Year College Degree & 11 & $5.3 \%$ & & & \\
\hline 4- Year College Degree & 90 & $43.5 \%$ & & & \\
\hline Masters Degree & 26 & $12.6 \%$ & & & \\
\hline Doctoral Degree & 9 & $4.3 \%$ & & & \\
\hline
\end{tabular}




\section{Data Analysis and Findings}

H1: "Pleasant" consumers will be more susceptible to making impulsive decisions compared to "unpleasant" consumers.

\begin{tabular}{|c|c|c|c|c|c|c|}
\hline \multicolumn{7}{|c|}{ Coefficients $^{a}$} \\
\hline \multirow{2}{*}{\multicolumn{2}{|c|}{ Model }} & \multicolumn{2}{|c|}{ Unstandardized Coefficients } & \multirow{2}{*}{$\begin{array}{c}\text { Standardized } \\
\text { Coefficients }\end{array}$} & \multirow[b]{2}{*}{$t$} & \multirow[b]{2}{*}{ Sig. } \\
\hline & & B & Std. Error & & & \\
\hline \multirow[t]{3}{*}{1} & (Constant) & 4.176 & .146 & & 28.635 & .000 \\
\hline & X101 & .078 & .029 & 181 & 2.671 & .008 \\
\hline & X102 & -.032 & .029 & -.076 & -1.119 & .265 \\
\hline
\end{tabular}

\section{a. Dependent Variable: $\mathrm{X} 100$}

Results:H1 was supported as X101 (the "pleasant" consumers) are more susceptible to making impulsive purchasing decisions compared to X102 (the "unpleasant" consumers). This can be seen through the level of significance of .008 . For this test we set X100, Puri's CIS, as the dependent variable and tested the means of X101 and X102 against X100.

H2: "Pleasant" consumers will spend more money than "unpleasant consumers will
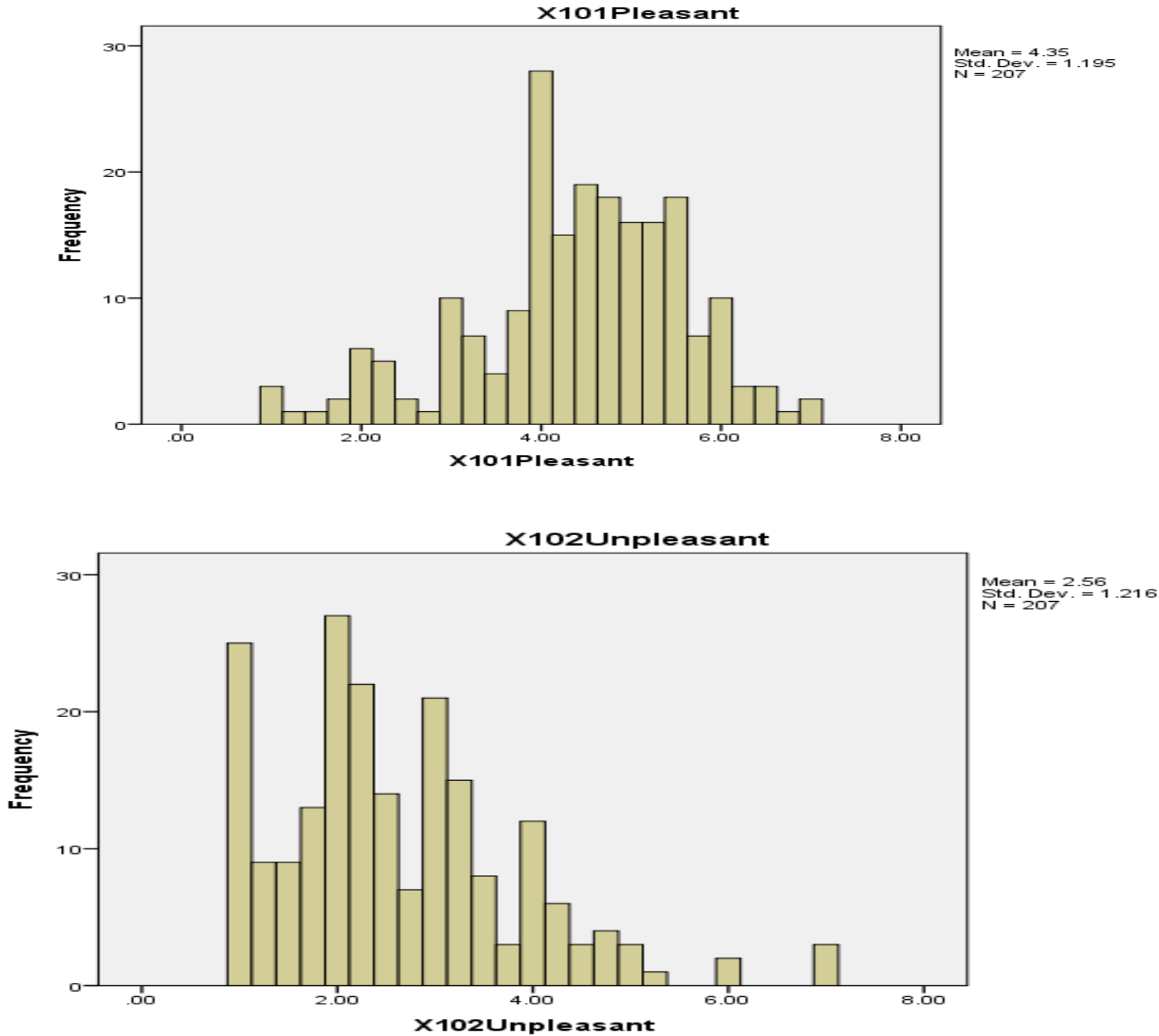
Results:H2 is supported as, out of a 7-point scale, the "pleasant consumer" (X101) mean was 4.37. The "unpleasant consumer" (X102) mean was a 2.58. This indicates that a consumer who is "pleasant" is more likely to agree when asked if he or she would be willing to spend more money while shopping.

H3:Demographic variables such as education, age, gender, and income make a consumer more susceptible to making an impulsive purchasing decision.

\section{Education}

\begin{tabular}{|c|c|c|c|c|c|}
\hline \multicolumn{6}{|c|}{ ANOVA } \\
\hline & $\begin{array}{l}\text { Sum of } \\
\text { Squares }\end{array}$ & df & Mean Square & $\mathrm{F}$ & Sig. \\
\hline $\begin{array}{l}\text { Between Groups } \\
\text { Within Groups } \\
\text { Total }\end{array}$ & $\begin{array}{r}1.124 \\
54.358 \\
55.482 \\
\end{array}$ & $\begin{array}{r}5 \\
201 \\
206 \\
\end{array}$ & $\begin{array}{l}.225 \\
.270\end{array}$ & .831 & .529 \\
\hline \multicolumn{6}{|c|}{ Age } \\
\hline \multicolumn{6}{|c|}{ ANOVA } \\
\hline$\times 100$ & & & & & \\
\hline & $\begin{array}{l}\text { Sum of } \\
\text { Squares }\end{array}$ & df & Mean Square & $\mathrm{F}$ & Sig. \\
\hline $\begin{array}{l}\text { Between Groups } \\
\text { Within Groups } \\
\text { Total }\end{array}$ & $\begin{array}{r}1.402 \\
54.081 \\
55.482\end{array}$ & $\begin{array}{r}5 \\
201 \\
206\end{array}$ & $\begin{array}{l}.280 \\
.269\end{array}$ & 1.042 & .394 \\
\hline
\end{tabular}

\section{Gender}

\begin{tabular}{|l|r|r|r|r|r||}
\hline \multicolumn{7}{|c|}{ ANOVA } \\
\hline \\
\hline
\end{tabular}

\section{Household Income}

\section{ANOVA}

$\times 100$

\begin{tabular}{|l|r|r|r|r|r||}
\hline & $\begin{array}{c}\text { Sum of } \\
\text { Squares }\end{array}$ & df & Mean Square & \multicolumn{1}{c|}{ F } & Sig. \\
\hline Between Groups & 1.529 & 6 & .255 & .945 & .464 \\
Within Groups & 53.953 & 200 & .270 & & \\
Total & 55.482 & 206 & & & \\
\hline
\end{tabular}


Results: H3 is not supported. Based on the level of significances for each of these four variables, there is no significant difference between any of them and the likelihood they would make a consumer more susceptible to impulsive purchasing decisions. These findings are contrary to previous studies and do not support or hypothesis.

\section{Conclusions and Recommendations}

The objective of this research was to determine if mood and certain impact consumer impulsivity selected demographics. As shown above in the Data Analysis and Findings, we were able to come to two different conclusions about how mood affects consumers. The first finding of great significance was that "pleasant" consumers are more susceptible to making impulsive purchasing decisions in comparison to an "unpleasant" consumer. This conclusion is based on and justified by the level of significance, which came out to be .008. The second finding that we found to be important states that "pleasant" consumers are willing to spend more money compared to "unpleasant" consumers. This was found because of comparing the two means of the "pleasant" and "unpleasant" consumers. Because of the mean for the "pleasant" consumers being higher than that of the "unpleasant" it can be concluded that a "pleasant" consumer is more likely to agree to spending more money when shopping. Obtaining these answers was critical for us as researchers because it not only pertained to our objective, but also points us in the right direction for making recommendations based from our results.

Our data shows that compared to demographics which had no relationship with impulsivity, mood is one of the biggest drivers for consumer behavior. With this knowledge we can now start to investigate what these would mean for a business and more specifically how they could ensure that customers in the store are most likely to become in a pleasant mood while in the store and at the point of purchase. One example of an industry that already exhibits this sort of behavior for attracting customers are supermarkets. It is certainly not by accident that the first scent that enters a patron's nose upon entering the store is of freshly made baked goods. Regardless if the customer notices the smell or not, subliminally, when they now think about that store, that supermarket has increased their chances of being thought of as a pleasant place, merely based off the warm aroma they deliberately placed close to the door. This same principle is what we highly recommend more stores investigate. Based off our research, we can confidently say that if retail stores assist customers into a pleasant mood, they in return increase their chances of that customer impulse buying and spending more money.

Our recommendation to managers would be to educate themselves more with situational influences and as well as implement variables around their store to try and promote "pleasant" feelings amongst consumers. This would mean to set up the store with bright and lively colors as well as upbeat music to keep the customer feeling "pleasant" leading to more sales. We would also recommend a very thorough and precise training method for all employees to teach them to interact with consumers to try and inhibit that "pleasant" sense of personability. This would include protocol on greeting the customer, helping them through the store, and giving recommendations to various products and services.

\section{Managerial Implications}

For almost all businesses, the bottom line is the same and that is to make the most money. We recognized this and realized that if we were to conduct research that could give a manager the knowledge on how to make more money, than we would have a successful project. This thought process is what eventually led us in choosing to examine what makes a consumer more likely to impulse spend upon entering a store. One of the main reasons we decided on this topic is primarily for how significant we believe the managerial benefits are from gaining further insight in this area. After processing our data and analyzing the results, our research shows a depiction of how impacted a consumer's behavior, specifically their spending habits and impulsivity, can be by their moods.

\section{Limitations}

Even though we took every step possible to help ensure that our research was done as accurately and as thoroughly as possible, there were certain limitations that could not be avoided. Though we firmly believe that none of these limitations majorly prohibited or constrained the outcome of our research, they are still necessary to address for future research purposes. Some of the limitations include:

- Participant responses- Our survey resulted in 207 useable responses. Increasing the amount of responses may have led to different and perhaps more thorough results. 
- Lack of respondent diversity- Due to our means of distribution many of our respondents were most current college students within the same age demographic. Broadening the respondent's demographics could give further insights as to what makes consumers impulse buy the most.

- Item Wording- Even though almost all our items were sourced from scholarly references, as with anything, the wording and meaning of all items are up to the interpretation of the respondent and their perception of a question or word could have been different than what we intended.

\section{Future Research}

As we hypothesized and our research concluded, a "pleasant" consumer is not only willing to spend more money compared to an "unpleasant" consumer, but also more susceptible to making impulsive purchasing decisions. As previously mentioned "emotion is viewed as a valenced affective reaction to perceptions of situations" meaning that outside forces (Richins, 1997) can influence the mood of a person. Our next step as market researchers would be to gain insight into exactly what those outside forces are and how a manager could implement them into a store. This could be done by examining the phenomenon of situational influences. It has already been shown that situational influences such as purchase task, social surroundings, physical surroundings, temporal effects, and antecedent states play a role in impacting consumer purchasing decisions (Kerin, 2013). Using this as a basis of rationale we would next look to learn the most effective ways for business to inhibit a "pleasant" mood amongst their patrons. Discovering how to make a consumer more likely to be in a pleasant mood upon entering a store gives us the opportunity to say to a manager, "we know what consumers will spend the most money in your store AND we know how to ensure your store does everything it can to attract these customers as best as possible", and that information is extremely valuable.

- Michael S. Pepe

- Michael S. Pepe, DBA, is an associate professor of marketing at Siena College. Dr. Pepe's teaching interests pertain to marketing strategy, marketing pedagogy, and marketing metrics. An integral component of Dr. Pepe's teaching methodology is application of all concepts that were developed during his 19 years of professional marketing experience. Michael is the first recipient in the Siena College School of Business to have received the Teaching, Research and Service Excellence awards. He has published in numerous academic journals.

\section{- Daniel C, Buff}

- Daniel C. Buff graduated from Siena College in 2015 as a marketing major. He has traveled to numerous remote places in the world as has researched cultural differences, presenting research in San Juan Puerto Rico. His interests include consumer behavior, international marketing, and marketing research. As a business development specialist, he promotes multilingual solutions to companies through independent prospecting while growing revenue through existing clients.

\section{References}

Anic', I.D., Piri Rajh, S.\&Rajh, E. (2010), "Razlike u stilovima odluc`ivanja potros`ac`a s obziromna spolispitanika u Hrvatskoj," Trz is te: časopis za trz is `̌nu teoriju i praksu, 22 (1),29-42.

Bagdare, S. \& Rajnish, J. (2013), "Measuring Retail Customer Experience,"International Journal of Retail \& Distribution Management, 41 (10), 790-804.

Chaudhuri, A., Aboulnasr, K., \& Ligas, M. (2010), "Emotional Responses on Initial Exposure to a Hedonic or Utilitarian Description of a Radical Innovation, Journal of Marketing Theory \& Practice, 18 (4) 339-359.

Ho, R., Potash, J., Fang, F.\&Rollins, J. (2015), "Art Viewing in Hospital Settings Effect on Mood," Health Environments Research and Design Journal, 8 (3), 30-43.

Kerin, R., Hartley, S, \& Rudelius, W.. Marketing the Core. 5th ed. New York: McGraw Hill, 2013. Print.

Mathai, S. \&Shanthaamani, V. (2016), "Materialism: Its impact on Impulse Buying Behaviour among the Retail Customers of Cochin,"International Journal of Management Research and Reviews, 6 (5),647-658.

Mayer, J.\&Gaschke, Y. (1988) "Brief Mood Introspection Scale: BMIS" Handbook of Marketing Scales 300-301

Mayer, J., Mamberg, M.\& Volanth, A. (1988), "Cognitive Domains of the Mood System," Journal of Personality, $56(3), 453-86, "$

Preeshl, A., George, G., \& Hicks, W. (2015), "The path to presence in performance through movement, physiological response, and mood,"Cogent Education; Abingdon, 2 (1), 1-14. 
Puri, R.(1996), "Measuring and Modifying Consumer Impulsiveness: A Cost-Benefit Accessibility Framework ," Journal of Consumer Psychology, 5 (2), 87-113.

Richins, M. (1997), "Measuring Emotions in the Consumption Experience," Journal of Consumer Research, 24 (2) , 127-46.

Rook, D. \&Fischer, R. (1995), "Normative Influences on Impulsive Buying Behavior," Journal of Consumer Research, 22, 305-13.

Shukla, P., Banerjee, M. \& Adidam, P.T. (2011), "The interplay between psychographic and socio-demographic factors on consumers' attitude toward private label brands,"AMASummer Educators' Conference Proceedings, 312-313.

Tifferet, S. \&Herstein, R. (2012), "Gender differences in brand commitment, impulse buying,and hedonic consumption,"Journal of Product \& Brand Management, 21 (3),176-182.

Verplanken, B.\&Sato, A. (2011), "The Psychology of Impulse Buying: An Integrative Self-Regulation Approach," Journal of ConsumerPolicy, 34 (2), 197-210.

Vipul, P. (2010), "Impact of demographic factors on consumer response to sales promotions: anempirical study,"Advances in Management, 3 (10), 60-65.

Zeithaml, V.A. (1985), “The new demographics and market fragmentation, ” Journal of Marketing, 49 (3), 64-75. 


\section{APPENDIX}

The Consumer Impulsiveness Scale: CIS" (Puri 1996)

The Following Adjective Describes Me

Strongly (2)

Disagree (1)

Impulsive (1)

Careless (2)

Self-

Controlled (3)

Extravagant

(4)

Farsighted (5)

Responsible

(6)

Restrained (7)

Easily

Tempered (8)

Rational (9)

Methodical

(10)

Enjoy

Spending (11)

A Planner

(12)
(3)

(4)

(5)

(6)

Agree (7)

○

O

$\bigcirc$

0

0

0

0

0

0

$\bigcirc$

0 
Brief Mood Introspection Scale: BMIS" (Maver, 1988)

When I am feeling

, I tend to spend more money when shopping...

\begin{tabular}{|c|c|c|c|c|c|c|c|}
\hline & Strongly Disagree (1) & (2) & (3) & (4) & (5) & (6) & Strongly Agree (7) \\
\hline active (1) & & & & & & & \\
\hline calm (2) & & & & & & & \\
\hline caring (3) & & & & & & & \\
\hline $\begin{array}{l}\text { content (4) } \\
\text { con }\end{array}$ & & & & & & & \\
\hline happy (5) & & & & & & & \\
\hline lively (6) & & & & & & & \\
\hline loving (7) & & & & & & & \\
\hline peppy (8) & & & & & & & \\
\hline & & & & & & & ) \\
\hline
\end{tabular}


When I am feeling , I tend to spend more money when shopping...

\begin{tabular}{|c|c|c|c|c|c|c|c|}
\hline & $\begin{array}{l}\text { Strongly } \\
\text { Disagree (1) }\end{array}$ & (2) & (3) & (4) & (5) & (6) & $\begin{array}{l}\text { Strongly } \\
\text { Agree (7) }\end{array}$ \\
\hline drowsy (1) & & & & & & & \\
\hline fed-up (2) & & & & & & & \\
\hline gloomy (3) & & & & & & & \\
\hline grouchy (4) & & & & & & & \\
\hline jittery (5) & & & & & & & \\
\hline nervous (6) & & & & & & & \\
\hline $\operatorname{sad}(7)$ & & & & & & & \\
\hline tired (8) & & & & & & & \\
\hline & & 0 & Q & O & ? & & \\
\hline
\end{tabular}

